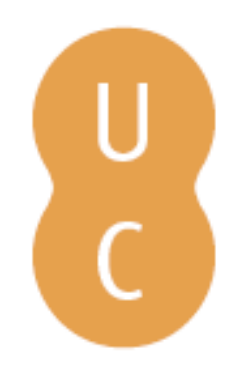

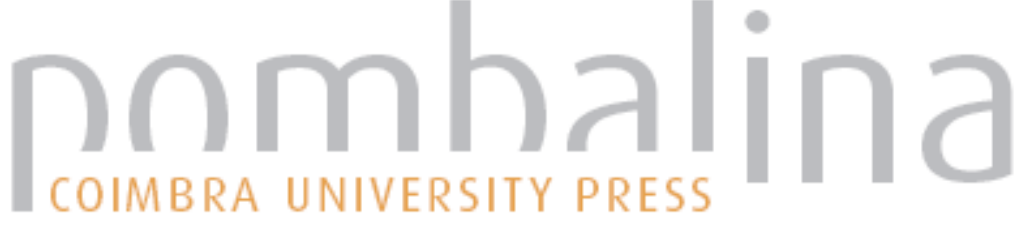

\section{Manifesto por um contrato de lealdade}

\author{
Autor(es): Maia, Alfredo
}

Publicado por: Imprensa da Universidade de Coimbra

URL

persistente: URI:http://hdl.handle.net/10316.2/38569

DOI: $\quad$ DOI:http://dx.doi.org/10.14195/978-989-26-0770-2_8

Accessed : $\quad$ 26-Apr-2023 11:36:45

A navegação consulta e descarregamento dos títulos inseridos nas Bibliotecas Digitais UC Digitalis, UC Pombalina e UC Impactum, pressupõem a aceitação plena e sem reservas dos Termos e Condições de Uso destas Bibliotecas Digitais, disponíveis em https://digitalis.uc.pt/pt-pt/termos.

Conforme exposto nos referidos Termos e Condições de Uso, o descarregamento de títulos de acesso restrito requer uma licença válida de autorização devendo o utilizador aceder ao(s) documento(s) a partir de um endereço de IP da instituição detentora da supramencionada licença.

Ao utilizador é apenas permitido o descarregamento para uso pessoal, pelo que o emprego do(s) título(s) descarregado(s) para outro fim, designadamente comercial, carece de autorização do respetivo autor ou editor da obra.

Na medida em que todas as obras da UC Digitalis se encontram protegidas pelo Código do Direito de Autor e Direitos Conexos e demais legislação aplicável, toda a cópia, parcial ou total, deste documento, nos casos em que é legalmente admitida, deverá conter ou fazer-se acompanhar por este aviso.

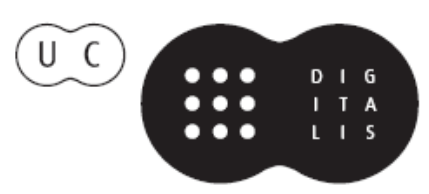



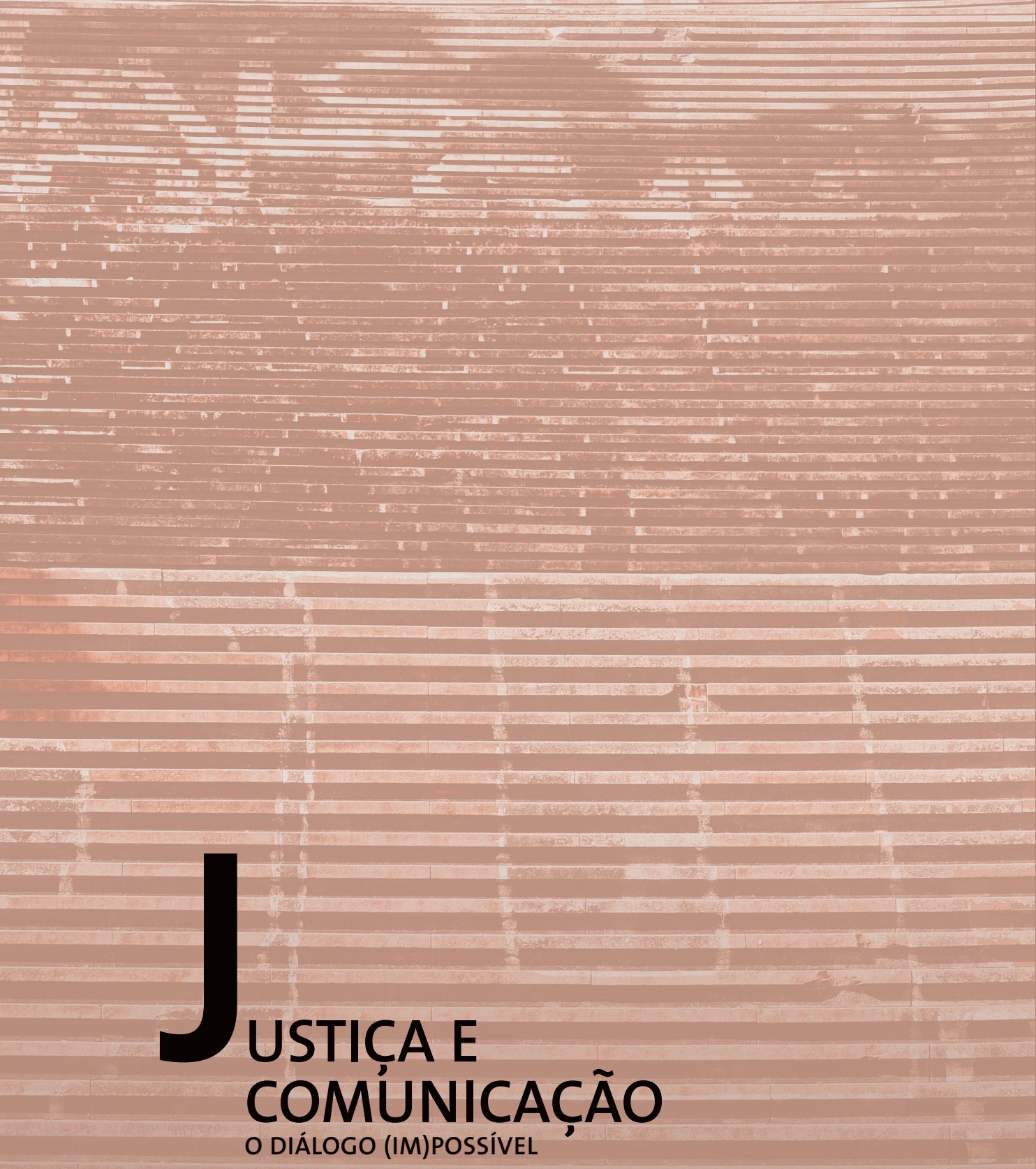

Rita Basilio Simões

Carlos Camponez

Ana Teresa Peixinho

ORGANIZAÇÃO 


\author{
Alfredo Maia \\ (Presidente da Direção do Sindicato dos Jornalistas)
}

\title{
MANIFESTO POR UM CONTRATO DE LEALDADE
}

É muito frequente a invocação do interesse público para justificar escolhas e opções editoriais e mesmo certas práticas e condutas de jornalistas, até quando conflituam com direitos das pessoas, convocando-se neste caso o princípio da concordância prática entre direitos e valores fundamentais em confronto.

Dizemos até, por vezes, que os jornalistas atuam em nome do interesse público, expressão que alguns entenderão exagerada, porque a ação em nome do interesse público implicaria de algum modo uma legitimidade democrática, que se entenderia não ser de reconhecer aos jornalistas, uma vez que não são eleitos nem investidos de um tal mandato por alguém com poderes legítimos para tal.

Atuar em nome do interesse público, atuam os poderes públicos para fazer prevalecer os interesses da coletividade, do bem comum, sobre os interesses particulares, podendo mesmo sacrificar estes.

Os jornalistas, no entanto, atuam ao serviço do interesse público legitimados pela coletividade e pelo Estado, não só através da ordem constitucional vigente, que desde logo alcandora a liberdade de expressão, o direito a informar e a ser informado e os direitos específicos dos jornalistas à dignidade de direitos fundamentais, mas também do reconhecimento que a comunidade de cidadãos confere à função da Imprensa nas sociedades democráticas.

Podemos até dizer que, nos estados democráticos, a liberdade de imprensa é tanto um resultado como uma condição da democracia, pois nenhuma sobreviveria sem a outra e cada uma só tem razão de ser em função da outra.

$O$ reconhecimento da função dos meios de informação pela comunidade é ainda fonte de legitimação, outorgando-lhe a missão de servir 
o interesse público - mesmo até em condições politicamente adversas, não democráticas ou com entorses à democracia - atuando em benefício do bem comum, mesmo que seja necessário, em certas circunstâncias, agir ao arrepio das normas legais, precisamente em ordem a satisfazer um interesse incontestável.

Por exemplo, a violação do segredo de justiça para denunciar o recurso à tortura como meio - ilícito e absolutamente condenável - de obtenção de uma confissão corresponde até a um imperativo de consciência irrenunciável.

Aliás, a lei penal, a doutrina e a jurisprudência, tanto dos tribunais nacionais como do Tribunal Europeu dos Direitos do Homem, têm reafirmado com clareza o princípio da exclusão da ilicitude e legitimado a conduta dos jornalistas quando esta justamente persegue o interesse público, o bem comum, mesmo quando contende com o "interesse público" representado pelo Estado, precisamente porque a informação livre se destina a capacitar os cidadãos a melhor escrutinarem o exercício dos poderes do Estado.

Note-se que o reconhecimento desse poder de escrutínio popular mediado pela Imprensa é um princípio fundador do próprio conceito de liberdade de imprensa e de legitimação do jornalismo, que entre nós tem as suas raízes modernas nas Bases da Constituição de 1821, aliás um passo inaugural da rutura da imprensa com o controlo ideológico do Antigo Regime.

“O Poder Legislativo não se distingue senão pela sabedoria das suas Leis e só uma contínua vigilância da sua parte é que pode manter a observância da Constituição: tirada a liberdade de Imprensa, como poderá ser informado das infrações da Constituição?", refletia o deputado José António Guerreiro às Cortes Gerais Extraordinárias e Constituintes de 1821.

Numa tentativa de estabelecer um conceito jornalístico de interesse público, podemos dizer que este se observa mediante o fornecimento, pelos jornalistas, de elementos informativos que habilitem os cidadãos a ter um olhar mais amplo e mais profundo sobre a vida, a fazer escolhas e a tomar decisões esclarecidas e refletidas com impacte na sua vida pessoal e na sua vida em comunidade.

Por isso, o interesse público só pode ser um objetivo (também no sentido de uma garantia para a decisão informada dos cidadãos) e não 
uma capa de proteção para consciências espúrias ou um embuste para satisfazer caprichos (voyeurismo, por exemplo)...

Embora faça parte do vasto argumentário do discurso de autolegitimação dos media e do jornalismo, a invocação do interesse público e a sua verificação e validação não são sequer pertença exclusiva do jornalista cuja conduta seja suscetível de reparo.

Caber-lhe-á, sem dúvida, essa apreciação, logo na primeira instância que é sempre a sua consciência, e na ponderação ética - bem sei, íntima e tantas vezes dolorosa! Mas, em última análise, é aos tribunais que cabe decidir da relevância de tal interesse e se pode afastar a ilicitude da conduta verificada sob a invocação desse interesse, sem embargo do juízo que também os pares e o público também elaborem.

O interesse público deve constituir sempre uma referência na atuação do jornalista, exigindo uma avaliação constante do seu dever de lealdade para com o público, as fontes de informação e com as pessoas objeto das suas notícias.

Este triângulo virtuoso - público/fontes/visados - deve estar permanentemente presente no exercício do juízo crítico que tem de servir de timoneiro da nossa conduta quotidiana, imposto por um dever de lealdade para com todos esses elementos integrantes do processo comunicacional.

A nossa atividade existe em função do público, do seu interesse; é a ele que servimos, para satisfazer as suas necessidades, esclarecer as suas dúvidas e responder aos seus anseios. Sem as fontes de informação, não seria possível habilitar os cidadãos com informação necessária para compreender o mundo e a agir nele. Sem os visados (que são também público e são também fontes), não haveria simplesmente objeto de notícia. Mas é bom que não transformemos os visados em matéria-prima de uma indústria destituída de valores e indiferente à matriz ética que deveria enformar o seu carácter.

Um dever de lealdade tem consequentemente implícito um pacto de lealdade, aliás um verdadeiro contrato com esse triângulo virtuoso e virtuoso também e ainda, mesmo quando o nosso olhar subjetivo sobre "certos" visados não resiste à tentação da desqualificação cívica e à depreciação do carácter, como é tantas vezes patente na informação sobre casos de justiça. 
Esse contrato assenta existe porque a contraprestação pelo serviço dos media e dos jornalistas não se circunscreve à mera aquisição do bem de consumo que é o jornal impresso ou a audiência de rádio ou televisão, na medida em que está imanente à nossa relação profissional com esse triângulo, um bem que, não sendo transacionável, constitui, na verdade, o capital de maior importância - a credibilidade dos media e dos jornalistas.

De modo que o público, as fontes e os próprios visados sabem retribuir o nosso trabalho com o reconhecimento da nossa credibilidade, renovando a confiança na nossa missão e revalidando a outorga de legitimidade do serviço ao interesse público, que é o núcleo central e irrenunciável da nossa profissão, balizada por uma deontologia - uma ciência dos deveres! - que vai além das próprias normas jurídicas e que justamente legitima a nossa intervenção no espaço público.

É por isso que costumamos dizer que o primeiro compromisso do jornalista é para com a verdade - condição essencial da lealdade. Mas a verdade não pode ser alcançada a qualquer preço, pois há circunstâncias - e são muitas - em que a busca da verdade pode ter de ceder perante direitos e valores que não podem ser sacrificados.

Por exemplo, a transcrição de escutas existentes em processos, e especialmente até as deixadas fora deles por penalmente irrelevantes, constitui um ato extraordinariamente arriscado, e tantas vezes de utilidade duvidosa, do ponto de vista do interesse público, para não dizer uma violação desproporcionada e gratuita de garantias dos cidadãos e dos seus mais elementares direitos de personalidade, que causa compreensível perplexidade aos cidadãos.

É certo que há decisões de tribunais, algumas até recentes, reconhecendo o relevante interesse público do traslado de certas transcrições para a imprensa, mas que isso não sirva de biombo de legitimidade para ocultar uma prática que nos deve manter alerta: a devassa em duplicado, e além do mais alcançando uma amplitude pública de grandes proporções, de conversações tidas na convicção de que se encontravam ao abrigo da curiosidade alheia e cujo conteúdo pode não ser exclusiva ou predominantemente ilícito.

Uma conversação privada - telefónica ou presencial - é um reduto essencial da privacidade que duas ou mais pessoas livremente decidem 
partilhar entre si, a tal ponto que o seu conteúdo pode abranger até aspetos mais profundos da intimidade dos interlocutores, mutuamente consentido na convicção de que a envolve uma indestrutível cápsula de segredo.

Na verdade, uma escuta e a sua transcrição, organizando, sistematizando e perpetuando a memória de uma série de conversações (recordemos: as escutas ficam gravadas, são transcritas, analisadas, interpretadas, guardadas...) permite à polícia, às autoridades judiciárias e... aos jornalistas que a elas acedam saber muito mais da vida e até da intimidade dos escutados do que aquilo que eles próprios são capazes de recordar-se.

De algum modo a constituição de assistente em processo merece séria reserva, como método desleal de recolha de informações.

A divulgação de elementos processuais (e até sem relevância penal...) durante o inquérito, nas diversas fases do processo e até à margem do próprio julgamento - antes, durante e depois dele, se o houve - constitui uma prática que, se se justifica tantas vezes em razão do interesse público, introduz, por outro lado, um fator de desigualdade extraprocessual que não pode deixar de inquietar os cidadãos nem deixar indiferentes os jornalistas.

Ao contrário da arena do processo, e em particular a audiência de julgamento, a mediatização induz facilmente o risco, que deve ser muito bem ponderado, de uma das partes - e é geralmente o arguido - ser colocada em posição de desvantagem numa contenda em que ele próprio muitas vezes não pode terçar armas, ou só pode fazê-lo apenas em reação, num segundo momento, ao divulgado, geralmente obtendo menos impacto... ou dando azo a novo pretexto para serem apresentados contra ele factos novos ou mesmo velhos mas reciclados.

Essa desigualdade de armas é mais gritante quando o poder do arguido é desproporcionado, especialmente no que tange à capacidade de reagir e influenciar reações, capacidade essa que se afere tantas vezes em função do meio social e económico em que gravita.

Este problema pode traduzir um grave risco de desdemocratização da cobertura jornalística da administração da Justiça, em violação do dever de lealdade já referido, e em risco de contaminação da própria Justiça, cada vez mais exposta à pressão externa, que a prazo pode 
levar à tentação de imposição de normas restritivas e antidemocráticas que afetem o próprio direito à informação.

É por isso que é necessário estar atento e reconhecer que esse é um problema muito importante na relação entre a Justiça e a Comunicação Social: ambas estão obrigadas a garantir a imparcialidade face às partes em conflito, mas esse desiderato torna-se mais difícil de alcançar quando: i) a voragem mediática se apodera do processo, por interesse legítimo do jornalismo na mediação da ação da Justiça ou do seu escrutínio; ii) por impulso de agentes processuais por motivos nem sempre claros; iii) ou por mera curiosidade mórbida ou por voyeurismo repreensível.

É preciso também ter presente o dever imprescritível do jornalista de atender sempre aos direitos das pessoas envolvidas no processo os arguidos em particular - dando-lhes a oportunidade de dizer pela sua boa a sua verdade antes de publicar a acusação sobre eles, mas sobretudo que não se esqueça que também na administração da Justiça e na procura da paz jurídica tudo tem um fim, um término.

De facto, não se compreende que inúmeros casos sejam sepultados numa vala de silêncio quando o julgamento vai perdendo interesse mediático ou, pior, quando a decisão dos tribunais vai no sentido da absolvição.

Ao longo dos anos, o Sindicato dos Jornalistas tem procurado passar uma mensagem fundamental: precisamente porque é exercido em nome do direito à mediação do escrutínio que o povo nem sempre pode fazer diretamente, a credibilidade da cobertura jornalística só ganha plenitude inteira se os jornalistas e os media se obrigarem a publicitar também as decisões relativas aos processos que tenham noticiado. Assim estará cumprido o contrato de lealdade também para com os visados e o público.

Finalmente, uma chamada de atenção para um problema muito importante: a informação em ambiente digital constitui uma forma perigosa de perpetuação da suspeita e de reapresentação sempiterna de presumíveis culpados, apesar de sobre a sua inocência terem transitado há muito decisões.

Uma simples busca num motor na Rede mostra como é fácil demonstrar, e basta sermos suficientemente preguiçosos, o ferrete eletrónico que continua a marcar muitas vidas e a segregar muitas pessoas honradas. 


\section{B I B L I O G R A F I A}

AFONSO, O. (2005). "Dever de reserva - O seu papel na jurisdição". In: AA VV, Balanço da reforma da acção executiva. Segredo de justiça e dever de reserva (Conselho Superior da Magistratura, II Encontro Anual - 2004). Coimbra: Coimbra Editora, pp. 147-154.

ALBINO, C. (2003). «Sim, a Ordem dos Jornalistas». In: Diário de Notícias, 2 de novembro.

AMSELEK, P. (1964). Méthode phénoménologique et théorie du droit. Paris: L.G.D. J.

ANTUNES, F. (1994). "Alta Autoridade está queimada». In: Jornal de Notícias, 14 de março.

AZNAR, H. (2005). Comunicação Responsável - A auto-regulação dos media. Porto: Porto Editora.

BARREIROS, J. A. (2005). "O dever de reserva nas profissões jurídicas». In: AA VV, Balanço da reforma da acção executiva. Segredo de justiça e dever de reserva (Conselho Superior da Magistratura, II Encontro Anual - 2004). Coimbra: Coimbra Editora, pp. 163-170.

BARTHES, R. (1984). O rumor da língua. Lisboa: Ed. 70, (trad. portuguesa).

BECKETT, K. e WESTERN, B. (2001). "Governing social marginality: welfare, incarceration and the transformation of state policy". In: Punishment and Society, 1, pp. 43-59.

BENHABIB, S. (2009). "Rumo a um modelo deliberativo de legitimidade democrática». In: MARQUeS, A. (ed.), A Deliberação Pública e suas Dimensões Sociais, Políticas e Comunicativas. Belo Horizonte: Autêntica Editora.

BERGEL, J-L. (1997). "Du concept de déontologie à sa consécration juridique». In: BERGEL, J-L, (org.), Droit et Déontologies Professionnelles. Aix-en-Provence: Librairie de l'Université.

BHATIA, V. K. (1993). Analysing Genre: Language Use in the Professional Setting. London: Longman.

BHATIA, V. K. (1994). Cognitive structuring in legislative provisions. In: GIBBONS, J. (ed.). Language and the Law. London: Longman.

BHATIA, V. K. (2010). Legal writing: specificity. Specification in legislative writing: accessibility, transparency, power and control. In: Coulthard, M. e Johnson, A. (eds.) 2010. The Routledge Handbook of Forensic Linguistics. London: Routledge.

BIRESSI, A. e NUNN, H. (2003). "Video justice: crimes of violence in social/media space». In: Space \& Culture, 6 (3): pp. 276-291.

BOBBIO, N. (1982). A teoria das formas de governo. Brasília: UnB.

BOBBIO, N. (2000). O futuro da democracia. São Paulo: Paz e Terra.

BOHMAN, J. (2000). "The division of Labor in Democratic Discourse: Media, Experts, and Deliberative democracy». In: Chambers, S. and Costain, A. N. (org). Deliberation, Democracy and the Media. Maryland: Rowman \& Littlefield Publishers. 
BOTTOMS, A. E. (1995). «The philosophy and politics of punishment and sentencing». In: Clakson, C. and Morgan, R. (eds.). The Politics of Sentencing Reform. Oxford: Clarendon Press.

BRES, J. (2005). "Savoir de quoi on parle: dialogue, dialogal, dialogique; dialogisme, polyphonie...» In: Bres, J.; Haillet, P.P.; Mellet, S.; Nølke, H. e Rosier, L. (dirs.). Dialogisme et polyphonie. Approches linguistiques. Bruxelles: De Boeck.

BRKIC, J. e ANDERSON, N. (1988). Drafting and Interpreting Legal Documents. In: Kevelson, R. (ed.). Law and Semiotics. Vol. 2. New York: Plenum Press.

CALHOUN, C. (1996). "Introduction: Habermas and the public sphere». In: Calhoun, C. (ed.) Habermas and the Public Sphere. 4. ${ }^{\mathrm{a}}$ ed., Cambridge: MIT Press, pp. 1- 48.

CAMPS, V. (2004). «Instituiciones, agencias y mecanismos de supervisión mediática». In: CONILL SANCHO, J.; GONZÁLEZ, V. (coords.). Ética de los Medios - Una apuesta por la ciudadanía audiovisual. Barcelona: Editorial Gedisa.

CANIVET, G. e JOLY-HURARD, J. (2004). La déontologie des magistrats. Paris: Dalloz.

CANotilho, G. e MOReira, V. (2007). Constituição da República Portuguesa Anotada, vol. I. Coimbra: Coimbra Editora.

CARAPINHA, M. C. (2006). Contributos para a análise da linguagem jurídica e da interacção verbal em sala de audiências. Dissertação de Doutoramento (não publ.). Coimbra: Faculdade de Letras.

CARMO, R. do (2005). "O dever de reserva - O dever de informar: algumas achas para o debate». In: AA VV, Balanço da reforma da acção executiva. Segredo de justiça e dever de reserva (Conselho Superior da Magistratura, II Encontro Anual -2004). Coimbra: Coimbra Editora, pp. 155-162.

CARPINI, M. D. e WILliAMS, B. A. (2001). «Let Us Infotain You: Politics in the New Media Environment». In: Bennet, W. L.; Entman, R. M. (eds). Mediated politics: communication in the future of democracy. Cambridge: Cambridge University Press, pp. 160-181.

CASTELLS, M. (1999). O poder da identidade (A era da informação: economia, sociedade e cultura; v.2). São Paulo: Paz e Terra.

CHERMAK, S. M. (1995). Victims in the News. Crime and the American News Media. Boulder, San Francisco, Oxford: Westview.

CHIBNALL, S. (1977). Law-and-Order News: An Analysis of Crime Reporting in the British Press. London: Tavistock Publications.

CHRISTIE, G. C. (1964). "Vagueness and Legal Language». In: Minnesota Law Review, 48.

COHEN, J. (1997). Deliberative Democracy. Cambridge: MIT Press.

COHEN, J. (2009). "Deliberação e legitimidade democrática». In: Marques, A. (ed.). A Deliberação Pública e suas Dimensões Sociais, Políticas e Comunicativas. Belo Horizonte: Autêntica Editora.

COHEN, S. (2002). Folk Devils and Moral Panics. The Creation of the Mods and Rockers, 3. ${ }^{\mathrm{a}}$ ed. London, New York: Routledge.

COHEN, S. e YOUNG, J. (1973). The Manufature of News: Deviance, Social Problems and the Mass Media. London: Constable.

CONSELHO REGULADOR (2006). Parecer Relativo ao Anteprojecto da Proposta de Lei que Altera o Estatuto dos Jornalista - Parecer 2/2006.

CORNU, G. (2000). Linguistique Juridique. $2^{\text {a }}$. Ed. Paris: Montchrestien.

CORNU, D. (1994). Journalisme et Vérité. Genebra: Labor et Fides.

CORREIA, J. C. (2005). Sociedade e Comunicação: Estudos sobre Jornalismo e Identidades. Covilhã: UBI. 
COULTHARD, M. e JOHNSON, A. (2007). An Introduction to Forensic Linguistics. Language in Evidence. London: Routledge.

COUlthARD, M. e JOHNSON, A. (eds.) (2010). The Routledge Handbook of Forensic Linguistics. London: Routledge.

CURTIS, P. (2001). Jack the Ripper and the London press. New Haven: Yale University Press.

DOUGLAS, M. (1986). How Institutions Think. New York: Syracuse University Press.

DRYZEK, J. (2004). "Legitimacy and economy in deliberative democracy» In: Farrely, C. Contemporary Political Theory: a Reader. London: Sage.

DRYZEK, J. (2000). Deliberative Democracy and Beyond: Liberals, Critics, Contestations. Oxford: Oxford University Press.

DUBOUCHET, P. (1990). Sémiotique Juridique. Paris: PUF.

DUCROT, O. (1982). La notion de sujet parlant. In: Cahier du Groupe de Recherches sur la Philosophie et le langage, 2. Grenoble: Université de Grenoble.

DUCROT, O. (1984). Le Dire et le dit. Paris: Minuit.

DURKHeIM, É. (1977). A Divisão do Trabalho Social, Vol. 1, trad. de M. I. Freitas. Lisboa: Editorial Presença.

EAGLETON, T. (2000). Ideology: an Introduction. 7. ${ }^{\mathrm{a}}$ ed. London: Verso.

ELSTER, J. (1986). "The Market and the Forum: Three Varieties of Political Theory". In: Elster, J.; Hylland, A. (eds). Foundations of Social Choice Theory, Cambridge: Cambridge University Press, pp. 104-132.

ELSTER, J. (1998). Deliberative Democracy. Cambridge: Cambridge University Press.

ERICSON, R., BARANEK, P. e CHAN, J. (1989). Negotiating Control: A Study of News Sources. Toronto: University of Toronto Press.

ESSER, F. (1999). "Tabloidization of news. A comparative analysis of Anglo-American and German Press Journalism». In: European Journal of Communication, pp. 291-324.

FARIA, J. E. (1986). "A Reforma do Ensino Jurídico». In: Revista Crítica de Ciências Sociais, 21.

FERNANDES, P. C. (2008). "Justiça e media: legitimação pela comunicação». In: Revista do CEJ $\left(n .^{\circ} 10\right)$, pp. 311-346.

FIGUEIREDO, C. e COSTA, R. (1990). "Alta Autoridade da discórdia». In: Expresso - Suplemento A4, 27 de janeiro.

FONSECA, J. (1994). "O lugar da Pragmática na Teoria e na Análise Linguísticas». In: Pragmática Linguística. Introdução, Teoria e Descrição do Português. Porto: Colecção Linguística/Porto Editora, n. ${ }^{\circ} 5$.

FOUCAUlT, M. (1991). Vigiar e Punir: Nascimento da Prisão. 9. ${ }^{a}$ ed., trad. de L. M. P. Vassallo. Petrópolis: Vozes.

FOX, R. L. e SICKEL, R. V. (2001). Tabloid Justice: Criminal Justice in an Age of Media Frenzy. London: Lynne Rienner Publishers Boulder.

FRANKLIN, B. (1997). Newszak \& News Media. London: Hodder Arnold.

FRASER, N. (1996). "Rethinking the public sphere: a contribution to the critique of actually existing democracy» In: Calhoun, C (ed.) Habermas and the Public Sphere. 4. ${ }^{a}$ ed., Cambridge: MIT Press, pp. 109-142.

FRIEDMAN, L. M. (1964-1965). Law and its Language. In: George Washington Law Review, p. 33.

FUENTES GONZÁLEZ, D. (1997). Algunas aportaciones de la sociolingüística al campo del derecho. In: Delgado León, F.; Calero Vaquera, M. L. e Osuna García, F. (eds.), (1998). 
Actas del II Simposio de Historiografía Lingüística. Córdoba: Servicio de Publicaciones de la Universidad de Córdoba.

GALVÃO TELLES, I. (2000). Introdução ao Estudo do Direito. Vol. II. 10 ${ }^{\mathrm{a}}$ ed. Coimbra: Coimbra Editora.

GARAPON, A. (1998). O guardador de promessas. Lisboa: Instituto Piaget.

GARLAND, D. (2001). The Culture of Control. Oxford: Oxford University Press.

GARMENT, S. (1991). Scandal: The Culture of Mistrust in American Politics. New York: Times Books.

GEYH, C. G. (2006). Preserving Public Confidence in the Courts in an Age of Individual Rights and Public Skepticism. http://ssrn.com/abstract=933699: Indiana University School of Law-Bloomington.

GIBBONS, J. (ed.) (1994). Language and the Law. London: Longman.

GIBBONS, J. (2003). Forensic Linguistics. An Introduction to Language in the Justice System. Oxford: Blackwell.

GIBBONS, J. e TURELL, M. T. (eds.) (2008). Dimensions of Forensic Linguistics. Amsterdam: John Benjamins Publishing Company.

GOLDMAN, L. (1994). Accident and absolute liability in anthropology. In: Gibbons (ed.). Language and the Law. London: Longman.

GOODRICH, P. (1987). Legal discourse. Studies in Linguistics, Rhetoric and Legal Analysis. London: Macmillan.

GRABER, D. A. (1980). Crime News and the Public. New York: Praeger.

GREER, C. e JEWKES, Y. (2005). "Extremes of Otherness: Media Images of Social Exclusion». In: Social Justice, 32 (1), pp. 20-31.

GREIMAS, A. J. (1976). Analyse sémiotique d'un discours juridique. In Greimas, A. J.. Sémiotique et sciences sociales. Paris: Seuil.

GRICE, P. (1975). Logic and Conversation. In: Cole, P.; Morgan, J. L. (eds.). Syntax and Semantics 3: Speech Acts. New York: Academic Press.

GUTMANN, A. e THOMPSON, D. (2007), "O que significa democracia deliberativa", In: Revista Brasileira de Estudos Constitucionais, Belo Horizonte, Ed. Fórum, 2007, pp. 17-78.

HABERMAS, J. (1996). Between Facts and Norms. Contributions to a Discourse Theory of Law and Democracy, Cambridge, MA: MIT Press.

HABERMAS, J. (1996), "Three Normative Models of Democracy» In: Benhabib, S. (ed.) Democracy and Difference. Princeton, NJ: Princeton University Press.

HABERMAS, J. (1997). Direito e Democracia - Entre facticidade e validade, vol. II. Rio de Janeiro.

HABERMAS, J. (1998). The Structural Transformation of the Public Sphere: An Inquiry into a Category of Bourgeois Society, 9. ${ }^{\mathrm{a}}$ reimp., trad. de T. Burger. Cambridge, MA: MIT Press.

HABERMAS, J. (2002). "Prefacio a la Nueva Edición Alemana de 1990". In: Historia y Crítica de la Opinión Pública: La Transformación Estructural de la Vida Pública, trad. de F. Gil Martín, $7^{\text {a }}$. reimp., Barcelona: Gustavo Gilli.

HALl, S., CRITCHER, C., JEFFERSON, T., CLARKE, J. e ROBERTS, B. (1978). Policing the Crisis: Mugging, the State, and Law and Order, London: The MacMillan Press.

HARRIS, S. (1994). Ideological exchanges in British magistrates courts. In: Gibbons, J. (ed.). Language and the Law. London: Longman.

HJARVARD, S. (2008). "The Mediatization of Society: a Theory of the Media as Agents of Social and Cultural Change». In: Nordicom Review 29, 2, pp. 105-134. 
HOEY, M (1985). "The Statute as Discourse and the Lawyer as Linguist». In: Hall, R. A. J. (ed.) The Eleventh LACUS Forum 1984. Columbia: Hornbeam Press.

HONNETH, A. (1995). The Fragmented World of the Social: Essays in Social and Political Philosophy. New York: SUNY Press.

HUTCHINGS, P. (1999). «Spectacularizing crime: ghostwriting the law». In: Law and Critique, 10: pp. 27-48.

JACKSON, B. S. (1995). Making Sense in Law. Linguistic, Psychological and Semiotic Perspectives. Liverpool: Deborah Charles Publications.

JALALI, C. (2005). "Nova governação nova cidadania? Os cidadãos e a política em Portugal». In: Revista de Estudos Politécnicos, vol. II, n. ${ }^{\circ} 4$.

JIMÉNEZ, F. J. (1994). «Posibilidades y limites del escandalo politico como una forma de control social». In: REIS Revista Española de Investigaciones Sociológicas, pp. 7-36.

KELSEN, H. (1934). "The pure theory of law, its methods and fundamental concepts". In: Law Quarterly Review, n. ${ }^{\circ} 50$.

KISSELER, L., e HEIDEMANN, F. (2006). «Governança pública: novo modelo regulatório para as relações entre Estado, mercado e sociedade?». In: Revista da Administração Pública, 40 (3), Rio de Janeiro, Maio/Junho.

LAMBERT, P. (2004). "Le devoir de réserve et les notions voisines». In: AA VV. Actes de la Table Ronde organisée par l' Institut d'Études sur la Justice, le 17 octobre 2003, Bruxelles: Bruylant, pp. 9-19.

LEVI, J. N. e WALKer, A. G. (eds.) (1990). Language in the Judicial Process. New York: Plenum Press.

MACHADO, H. e SANTOS, F. (2009). A moral da justiça e a moral dos media: Julgamentos mediáticos e dramas públicos (Oficina do CES $n .^{\circ} 333$ ). Coimbra: CES.

MACHADO, H. e SANTOS, F. (2008). Crime, drama e entretenimento. O caso Maddie e a meta-justiça popular na imprensa portuguesa (Oficina do CES n. ${ }^{\circ}$ 308). Coimbra: CES.

Machado, J. (2002). Liberdade de Expressão. Dimensões constitucionais da esfera pública no sistema social. Coimbra: Coimbra Editora.

MACHADO, J. B. (2002). Introdução ao Direito e ao Discurso Legitimador. (13 $3^{\mathrm{a}}$ reimp.) Coimbra: Almedina.

MALEY, Y. (1994). The Language of the Law. In: Gibbons, J. (ed.). Language and the Law. London: Longman.

MANIN, B. (1987). "On Legitimacy and Political Deliberation». In: Political Theory, 15, pp 338-368.

MANSBRIDGE, J. (1999). "Everyday talk in deliberative system» In: Macedo, S. (ed.). Deliberative Politics: Essays on Democracy and Disagreement. New York: Oxford University Press.

MARMOR, A. (2008). "What Does the Law Say?»In: Analisi e diritto 2007. Ricerche di giurisprudenza analitica. Torino: G. Giappichelli Editore.

MASCARENHAS, Ó. (1998) "Por uma carta 98 da auto-regulação». In: AAVV. $3 .^{\circ}$ Congresso dos Jornalistas Portugueses - Conclusões, teses, documentos, Lisboa, Comissão Executiva do III Congresso dos Jornalistas Portugueses.

MASON, P. (2006) «Lies, distortion and what doesn't work: monitoring prison stories in the British media». In: Crime Media Culture, 2 (3), pp. 251-267.

MATHIESEN, T. (1995). "The eagle and the sun: on panoptical systems and mass media in modern society». In: Ericson, R. (ed.) Crime and the Media. Aldershot, Brookfield USA, Singapore, Sydney: Dartmouth, pp. 333-350. 
MATHIESEN, T. (2004). Essays on the creation of Acquiescense in Modern Society, Winchester: Waterside Press.

MATHIESEN, T. (2006). Prison on Trial, $3^{\mathrm{a}}$. ed., Winchester: Waterside Press.

MATOS, F. A. (2011). Responsabilidade Civil por Ofensa ao Crédito ou ao Bom Nome. Coimbra: Almedina.

MESQUITA, J. (1998). "Aprofundar a autonomia", In: AAVV. 3. ${ }^{\circ}$ Congresso dos Jornalistas Portugueses - Conclusões, teses, documentos. Lisboa: Comissão do III Congresso dos Jornalistas Portugueses.

MOREIRA, V. (1997). Auto-Regulação Profissional e Administração Pública. Coimbra: Almedina, 1997.

NEWBURN, T. e JONES, T. (2007). "Symbolizing crime control». In: Theoretical Criminology, 11(2), pp. 21-243.

OLSSON, J.(2004). Forensic Linguistics. An Introduction to Language, Crime and the Law. London: Continuum.

PAIXÃO, B. (2010). O escândalo político em Portugal (1991-1993 e 2002-2004). Coimbra: Minerva.

PATON, W. R. (1922). Polybius: The Histories, Volume III, Books 5-8 (Loeb Classical Library). London: Heinemann.

PRATT, J. (2007). Penal Populism, London, New York: Routledge.

PUTMAN, E. (1997). "Éthique des affaires et déontologie des professions d'affaires: réflexions sur la morale des marchands». In: BERGEL, J-L. (org.). Droit et Déontologies Professionnelles. Aix-en-Provence: Librairie de l'Université.

RAWLS, J. (1971). A Theory of Justice. Harvard: Harvard University Press.

RAWLS, J. (2001). O Direito dos Povos. São Paulo: Martins Fontes.

RIVERA BEIRAS, I. (2003). "State form, labor market and penal system: the new punitive rationality in context». In: Punishment Society, 7(2), pp. 167-182.

SANDERS, L. (1997). "Against deliberation». In: Political Theory, 25, pp. 347-376.

SANTOS, B. S. et al. (2009). A Justiça Penal: Uma Reforma em Avaliação. Coimbra: Centro de Estudos Sociais da Faculdade de Economia da Universidade de Coimbra.

SCHLESINGER, P. e TUMBER, H. (1994). Reporting Crime: The Media Politics of Criminal Justice. Oxford: Clarendon Press.

SCHLESINGER, P., TUMBER, H. e Murdock, G. (1995). "The media politics of crime and criminal justice». In: ERICSON, R. (coord.) Crime and the Media. Aldershot, Brokfield USA, Singapore, Sydney: Dartmouth, pp 397-420.

SCHUDSON, M. (1978). Discovering the news: a social history of American newspapers. New York: Basic Books.

SCHULZ, W. (2004). "Reconstructing Mediatization as an Analytical Concept». In: European Jounal of Communication Vol 19 (1), pp. 87-101.

SCHUMPETER, J. A. (1994). Capitalism, Socialism, and Democracy. London: Routledge.

SERRANO, E. (2007). "Pensar a regulação dos media numa sociedade em mudança». In: Comunicação e Sociedade ("Regulação dos media em Portugal»), vol. 11, Braga.

SHAPIRO, I. (1999). "Enough of deliberation: politics is about interest and power". In: Macedo, S. (ed.), Deliberative Politics: Essays on Democracy and Disagreement. New York: Oxford University Press.

SHETREET, S. e DESCHÊNES, J. (eds) (1985). Judicial Independence; the contemporary debate. Amsterdam: Martinus Nijhoff. 
SILVA, A. S., (2007). "A hetero-regulação dos meios de comunicação social». In: Comunicação e Sociedade, vol. 11, Braga.

SILVA, V. J. (2006). "Ordem e desordem jornalística». In: Diário de Notícias, 29 de Março.

SILVEIRINHA, M. J. (2004). Identidades, Media e Política: O Espaço Comunicacional nas Democracias Liberais, Lisboa: Livros Horizonte.

SILVEIRINHA, M. J. (2005). "Democracia deliberativa e reconhecimento: repensar o espaço político». In: Correia, J. C. Comunicação e Política. Covilhã: UBI.

SOURIOUX, J-L e LERAT, P. (1975). Le langage du droit. Paris: PUF.

STOFFEL-MUNCK, P., (1997). "Déontologie et moral». In: Bergel, J-L. (org.), Droit et Déontologies Professionnelles. Aix-en-Provence: Librairie de l'Université.

STYGALL, G. (2010). "Legal writing: complexity. Complex documents/average and not-so-average readers". In: Coulthard, M.; Johnson, A. (eds.) (2010). The Routledge Handbook of Forensic Linguistics. London: Routledge.

SURETTE, R. (2010). Media, crime, and criminal justice: images, realities and policies. $4 .{ }^{a}$ ed. Belmont: Wadsworth.

THOMAS, J. (1997). Judicial Ethics in Australia. Sydney: Law Book Co.

THOMPSON, J. (2005). "The new visibility". In: Theory, Culture E Society, 22(6),pp. 31-51.

THOMPSON, J. B. (2002). O escândalo político: poder e visibilidade na era da mídia. Petrópolis: Editora Vozes.

THORNTON, G. C. (1996). Legislative Drafting. London: Butterworth.

THUSSU, D. K. (2007). News as entertainment: the rise of global infotainment. London: Sage.

TIERSMA, P. M. (1993). «Linguistic Issues in the law». In: Language, 69, pp. 113-137.

TIERSMA, P. M. (2000). Legal Language. Chicago: The University of Chicago Press.

VALIER, C. (2002). Theories of Crime and Punishment. Harlow, New York: Longman.

VAN DIJK, T. A. (1990). La Noticia como Discurso: Comprensión, Estructura y Producción de la Información, Paidós: Barcelona.

VAN DIJK, T. A. (2005). Discurso, Notícia e Ideologia: Estudos na Análise Crítica do Discurso, trad. de Z. P. Coelho, Porto: Campo das Letras.

VAN OMMESLACHE, P. (1995) “L'autorégulation». In: AAVV, L'Autorégulation. Bruxelas: Bruylant.

VERDUSSEN, M. (2004). "Le devoir de réserve au regard de la jurisprudence de la Cour Européenne des Droits de l'Homme». In: AA VV, Actes de la Table Ronde organisée par l' Institut d' Études sur la Justice, le 17 Octobre 2003. Bruxelles: Bruylant, pp. 21-31.

VILlEY, M. (1974). "Préface». In: Archives de Philosophie du Droit, Tome XIX.

VILLEY, M., KALINOWSKI, G. e GARDIES, J-L. (1974). "Indicatif et impératif juridiques. Dialogue à trois voix". In: Archives de Philosophie du Droit, Tome XIX.

VIRALlY, M. (1966). "Le phénomène juridique». In: Revue de Droit Public.

WACQUANT L. (2001). "How penal common sense comes to Europeans: notes on the transatlantic diffusion of neoliberal doxa». In: European Societies, 1 (3), pp. 319-352.

WEICHER, M. E. e GOLDSCHMIDT, J. (2007). "The Expansion of the First Amendment in Judicial Elections: Another Cause for Reform». In: Loyola University Chicago Law Journal, pp. 833-894.

WEICK, K. E. (1995). Sensemaking in Organizations. London: Sage. 
WIENER, J. (1988). Papers for the millions; the new journalism in Britain, 1850-1914. New York: Greenwood.

WIIO, O. A. (1995). "Organizational communication. Contingent views». In: Goldhaber G.M.; Barnett G. A. (eds.). Handbook of Organizational Communication. Norwood: Ablex.

WILliAMS, G. (1945). Language and the Law (artigo em 5 partes). In: The Law Quarterly Review 61 (4 partes) e 62 (5. ${ }^{\mathrm{a}}$ parte).

WOLTON, D. (1995). "As contradições do espaço público mediatizado". In: Revista de Comunicação e Linguagens, 21-22, pp. 167-188.

YOUNG, I. M. (2000). Inclusion and Democracy. Oxford: Oxford University Press. 